\title{
Study on Sensitivity Improving of Fiber Bragg Grating Based pH Sensor
}

\author{
Xiongchang LIANG ${ }^{1,2}$, Shun'er CHEN ${ }^{1,2}$, Hongbin HUANG ${ }^{1,2}$, and Weiping LIU ${ }^{1,3^{*}}$ \\ ${ }^{1}$ Department of Electronic Engineering, Jinan University, Guangzhou, 510632, China \\ ${ }^{2}$ Key Laboratory of Optoelectronic Information and Sensing Technologies of Guangdong Higher Educational Institutes, \\ Jinan University, 510632, China \\ ${ }^{3}$ Optoelectronic and Fiber Sensing Institute of Beijing Pioptics, Beijing, 100176, China \\ ${ }^{*}$ Corresponding author: Weiping LIU_ E-mail:wpl@jnu.edu.cn
}

\begin{abstract}
The key factor of the sensitivity in the FBG-based pH sensor is analyzed in detail. A multi-thin-layer structure of the gel coated cover was proposed and implemented with a special process. The sensors with the coated thickness of $420 \mu \mathrm{m}, 500 \mu \mathrm{m}$, and $580 \mu \mathrm{m}$ were built up, respectively. The corresponding spectral shifts of $0.08 \mathrm{~nm}, 0.13 \mathrm{~nm}$, and $0.22 \mathrm{~nm}$ were detected when the $\mathrm{pH}$ sensors were soaked in the $\mathrm{pH}$ value of 3-9. Meanwhile, the sensor with the gel layer thickness of $580 \mu \mathrm{m}$ was measured in the optimum measurement time period with the $\mathrm{pH}$ value changing from 3-12, in which the detected sensitivity of $52 \mathrm{pm} / \mathrm{pH}$ was achieved in the $\mathrm{pH}$ range of 6-12.
\end{abstract}

Keywords: Fiber Bragg grating, hydrogel, pH sensor, sensitivity

Citation: Xiongchang LIANG, Shun'er CHEN, Hongbin HUANG, and Weiping LIU, "Study on Sensitivity Improving of Fiber Bragg Grating Based pH Sensor," Photonic Sensors, 2014, 4(1): 28-33.

\section{Introduction}

With advantages of high sensitivity, wavelength encoding and reflective measurement, etc. [1], fiber Bragg gratings (FBGs) have been proved to be high performance sensors in detecting physical quantities, such as the strain, temperature, displacement, acceleration. However, the FBG sensors designed for chemical detection are still in the stage of exploration, and the related studies are becoming the current research hotspots of the FBG.

Recently, a new kind of chemo-mechanicaloptical sensors based on the FBG has been proposed and studied for the measurement of one of the most important chemical parameters - the $\mathrm{pH}$ value of solution, in which the expanding or contracting in the volume of $\mathrm{pH}$ sensitive hydrogel coated on the FBG will result in shifts of the reflection spectrum of the FBG. Initially, I. Yulianti [2-3] proposed and studied the FBG-based $\mathrm{pH}$ sensor by using two aluminum disks attached at the end of the sensing region to prevent the axial expansion of $\mathrm{pH}$-sensitive hydrogel coated on the FBG. In this design, the structural complexity is introduced, and the measurement range is limited for the poor acid and alkali resistance of aluminum disks. After that, B. N. Shivananju [4] studied $\mathrm{pH}$ sensing by the single layer hydrogel coated FBG to obtain a sensor with the simple structure and large measurement range. However, the sensitivity of the sensor with single

Received: 1 July 2013/ Revised version: 21 September 2013

(C) The Author(s) 2013. This article is published with open access at Springerlink.com

DOI: 10.1007/s13320-013-0124-5

Article type: Regular 
layer hydrogel coated is just $3 \mathrm{pm} / \mathrm{pH}$. At present, FBGs-based $\mathrm{pH}$ sensors have not far reached a practical application level as there are some rough edges to be improved, among which, one of the important issues is to increase the detected sensitivity in the sensor.

In this paper, aiming at improving the sensitivity of FBG-based $\mathrm{pH}$ sensors with the simple gel layer structure, the principle of high sensitivity in the sensor is analyzed in detail, and the variational trend of the sensitivity in the FBGs pH sensor is discussed. Further, a multi-thin-layer structure of $\mathrm{pH}$-sensitive hydrogel of the FBGs-based $\mathrm{pH}$ sensor is proposed and implemented, in which many thin $\mathrm{pH}$-sensitive hydrogel layers are coated on the FBG with an improved coating process. As a result, the measuring sensitivity of the FBGs-based $\mathrm{pH}$ sensor is greatly improved within the range of the $\mathrm{pH}$ value $6-12$. The principles of the FBG-based $\mathrm{pH}$ sensor with the high sensitivity and building up of high sensitive $\mathrm{pH}$ sensors, as well as the test schemes are given in Section 2. The corresponding test results and the related discussion are expressed in Section 3, and then the conclusion is given in last section.

\section{Experimental measurement schemes}

\subsection{Principles of FBG-based pH sensor with high sensitivity}

In FBG-based $\mathrm{pH}$ sensors, the expansion or contraction of the $\mathrm{pH}$ sensitive gel, which is coated on the FBG, will apply a stress along the fiber grating, resulting in a change in the grating period in the FBG, sequentially and a change in the reflected wavelength $\left(\lambda_{B}\right)$, which is called the Bragg wavelength and can be expressed as

$$
\lambda_{B}=2 n_{\text {eff }} \Lambda
$$

where $n_{\text {eff }}$ is the effective refractive index of the fiber, which is a constant for certain fiber, while $\Lambda$ is the grating period. In a word, it is the stress in the pH sensitive gel layer coated on the FBG that causes the Bragg wavelength shift, in the case of the temperature of the sensor being kept constant.

Therefore, the Bragg wavelength can be expressed as following (1)

$$
\frac{\Delta \lambda_{B}}{\lambda_{B}}=K_{\varepsilon} \cdot \varepsilon
$$

where $\varepsilon$ is the axial stress of the FBG, which is caused by the expansion or contraction of the $\mathrm{pH}$ sensitive gel layer coated on the $\mathrm{FBG}$, and $K_{\varepsilon}$ is a constant.

The mechanical expansion mechanism in different layers of FBGs structure was studied by B. Sutapun [5], in which, the Pd coated layer on the FBG was used to sense $\mathrm{H}_{2}$ via the elastooptic effect. In the study, the stress applied on the FBG is given in the following equation:

$$
\varepsilon_{F}=\delta \frac{\left(b^{2}-a^{2}\right) Y_{P}}{a^{2} Y_{F}+\left(b^{2}-a^{2}\right) Y_{P}}
$$

where $a$ and $b$ are the radii of the FBG fiber (core and cladding) and the coated Pd layer on the FBG, respectively, while $Y_{F}$ and $Y_{P}$ are Young moduluses of the fiber and $\mathrm{Pd}$, and $\delta$ is the stress coefficient. As $Y_{F}=73 \mathrm{GPa}$ [6], $Y_{P}=128 \mathrm{GPa}$ [7], the applied stresses on the FBG versus different coated layer thicknesses are given in Fig. 1(a), in which, the stresses hardly increase when $b$ is beyond $250 \mu \mathrm{m}$.

In our case, however, things are totally different. Instead, the FBG is coated with the gel layer whose Young modulus, denoted as $Y_{H}$, is much smaller than that of the fiber $\left(Y_{F}\right.$ is in the order of dozens GPa, and $Y_{H}$ is only in the order of less than MPa [8]), so the axial stress in the FBG core can be simplified as

$$
\varepsilon_{F} \approx \delta \frac{\left(b^{2}-a^{2}\right) Y_{H}}{a^{2} Y_{F}}
$$

where $\delta$ is the stress coefficient proportioning to the $\mathrm{pH}$ value, and the related curve of $\varepsilon_{\mathrm{F}}$ versus the coated radius $b$ is shown as Fig. 1(b). It is observed from Fig. 1(b) and (4) that: firstly, $\varepsilon_{F} / \delta$ is much smaller in comparison with the case of the FBG coated with a metal layer like Pd; secondly, $\varepsilon_{F} / \delta$ is quite little when $b$ is small. As the thickness of the gel layer coated on FBGs in the present $\mathrm{pH}$ FBG 
based sensors is quite small, the measuring sensitivity is very low. It is obvious that $\varepsilon_{F} / \delta$ will be greater when $b$ increases, which will result in a larger Bragg wavelength shift, that is to say, a high sensitivity of the sensor can be achieved.

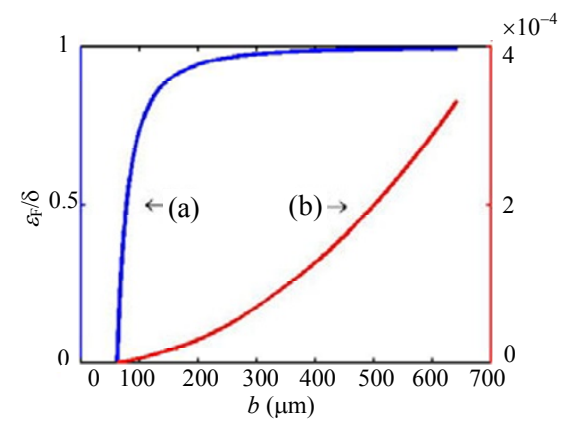

Fig. 1 Comparision between the Pd and the hydrogel coated layers: (a) stress on the FBG versus different radii $b$ of the Pd coated layer and (b) stress variation trend versus different radii $b$ of the hydrogel layer coated on the FBG.

\subsection{Building up of high sensitive FBG pH sensor and test schemes}

From the above analysis, it is clear that a higher sensitivity in the FBG-based $\mathrm{pH}$ sensor can be achieved by the way of getting a thicker gel layer coated on FBGs, in which the cylindrical symmetry along the fiber axis needs to be ensued. The symmetrical thickness of the gel layer, however, is not the only issue to be considered. Besides, the response time and tensile strength of the FBG sensor are the other factors needed to be taken into account. Therefore, in practical design, instead of purchasing a big radius in the gel layer, a moderate radius will be more reasonable for a high performance of the FBG-based $\mathrm{pH}$ sensor.

The hydrogel used to be coated on the FBG is a 2-hydroxyethyl methacrylate(HEMA)-acrylic acid (AA) comonomer gel sensitive to variations in the environmental $\mathrm{pH}$ [9]. As the $\mathrm{pH}$-sensitive hydrogel used is quite good at liquidity, which is hard to be coated on the fiber grating, a multi-thin-layer structure of the $\mathrm{pH}$ sensor is designed as shown in Fig. 2, where the so-called multi-thin-layer structure is built up via our unique coating-curing process, in which the coated thin thickness and the curing time need to be precisely controlled in order to make sure of the symmetry of the coated layer and the stick strength between layers.

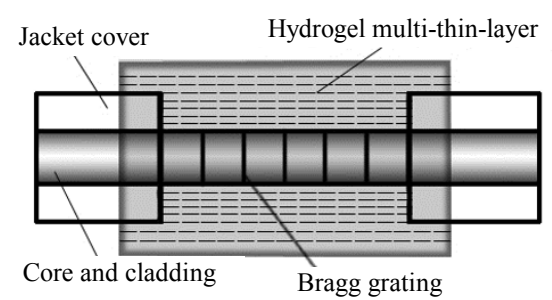

Fig. 2 Schematic diagram of a multi-thin-layer structure of the FBG-based $\mathrm{pH}$ sensor.

In our scheme, the gel layer thicknesses of $420 \mu \mathrm{m}, 500 \mu \mathrm{m}$, and $580 \mu \mathrm{m}$ were designed and built up for the experiment. The test setup is shown as Fig. 3, where an amplified spontaneous emission (ASE) was used as the broadband light source, which was coupled into the FBG pH sensor with the $2 * 2$ coupler. During the tests, the different Bragg wavelength shifts in the FBG pH sensor, in different time periods, were detected by the optical spectrum analyzer (OSA), corresponding to being soaked in different $\mathrm{pH}$ values of the solution, whose range was from 3.0 to 12.0 of the $\mathrm{pH}$ value.

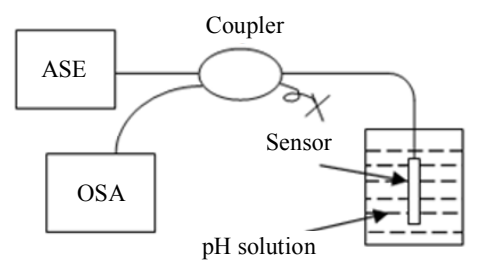

Fig. 3 Experimental test scheme for the FBG-based pH sensor.

Two measurement schemes have been carried out in our experiments, among which, the Bragg wavelength shifts in three FBG-based $\mathrm{pH}$ sensors with the gel layer thicknesses of $420 \mu \mathrm{m}, 500 \mu \mathrm{m}$, and $580 \mu \mathrm{m}$ versus different $\mathrm{pH}$ solutions and the Bragg wavelength shift of the $\mathrm{pH}$ sensor with a gel layer thickness of $580 \mu \mathrm{m}$ versus different $\mathrm{pH}$ solutions in the optimum measurement time period, were tested.

\section{Experimental result and discussion}

\subsection{Test results of $\mathrm{pH}$ sensors with different coated thicknesses}

The test reflected spectral shifts of the FBG- 
based $\mathrm{pH}$ sensors we prepared with different coated thicknesses, corresponding to the gel layer thicknesses of $420 \mu \mathrm{m}, 500 \mu \mathrm{m}$, and $580 \mu \mathrm{m}$, respectively, are shown in Fig. 4. It can be seen from the figure that the maximum wavelength shifts in the reflected spectra of the $\mathrm{pH}$ sensors were $0.08 \mathrm{~nm}$, $0.13 \mathrm{~nm}, 0.22 \mathrm{~nm}$, respectively, corresponding to the gel layer thicknesses of $420 \mu \mathrm{m}, 500 \mu \mathrm{m}$, and $580 \mu \mathrm{m}$, when the $\mathrm{pH}$ value of the solution changed from 3.0 to 9.0. It is obvious that the thicker the gel layer is, the greater the stress acting on the FBG will be, via the expansion of the hydrogel, as a result, the maximum shift of the Bragg wavelength is greater, which means a higher test sensitivity in the $\mathrm{pH}$ sensors. Besides, Fig. 4 suggests that the high sensitive response of the three sensors is main in the $\mathrm{pH}$ range of 6.0-9.0. The average sensitivities in this test range were worked out with the result of $15 \mathrm{pm} / \mathrm{pH}, 28 \mathrm{pm} / \mathrm{pH}$, and $53 \mathrm{pm} / \mathrm{pH}$, which corresponded to the gel layer thicknesses of $420 \mu \mathrm{m}$, $500 \mu \mathrm{m}$, and $580 \mu \mathrm{m}$, respectively. Comparing with the sensitivity of $3 \mathrm{pm} / \mathrm{pH}$ got with using the single hydrogel coated FBG in the previous research [4], the sensitivity in our case was improved by an order of magnitude. The test results showed that the FBG-based pH sensor with the thicker gel layer had higher sensitivity, which was consistent with the above analysis. Meanwhile, the $\mathrm{pH}$ sensor with a gel coated layer thickness of $580 \mu \mathrm{m}$ seems to have more practical value with higher sensitivity.

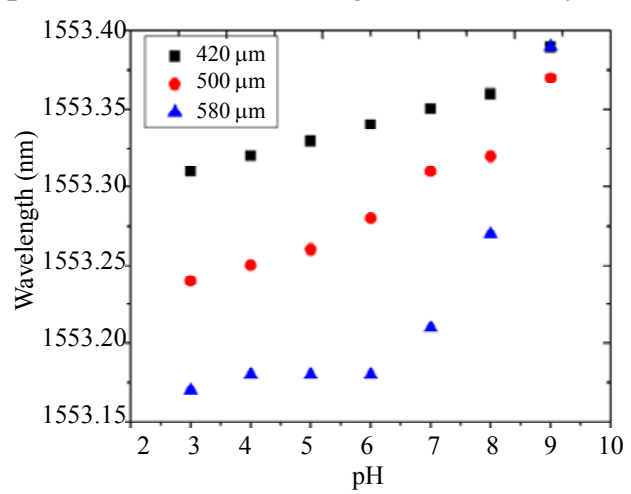

Fig. 4 Spectral shifts of FBG-based $\mathrm{pH}$ sensors versus different coating thicknesses (the Bragg wavelengths in the free state are $1553.35 \mathrm{~nm}, 1553.31 \mathrm{~nm}$, and $1553.21 \mathrm{~nm}$, respectively).

\subsection{Test results of $\mathrm{pH}$ sensors in the optimum measurement time period}

An additional study was undertaken to optimize the sensing performance of FBG-based $\mathrm{pH}$ sensors via the optimum measurement time. The affect of the polymerization time of $\mathrm{pH}$-sensitive hydrogel on the elastic modulus was studied by B. D. Johnson [9], in which the Young modulus of hydrogel had different values in different test time periods, and the maximum and stable value was in the test time period of $4 \mathrm{~min}$. It suggests that $4 \mathrm{~min}$ is the optimum measurement time and is a key factor in optimizing the sensing performance of the FBG-based $\mathrm{pH}$ sensors when (4) is also taken into consideration. Thus, the sensing performance of the $\mathrm{pH}$ sensor with a gel layer thickness of $580 \mu \mathrm{m}$ versus different $\mathrm{pH}$ solutions in the optimum measurement time period of $4 \mathrm{~min}$ was tested. In the test experiment, the Bragg wavelength of the FBG was $1544.26 \mathrm{~nm}$ in the free state, the bandwidth of it was $3 \mathrm{~dB}$, and the reflectivity of the grating was over $90 \%$ by the ultraviolet(UV)-writing technology [10]. The values of the Bragg wavelength were determined by the peak wavelength tracing through setting the resolution of the optical spectrum analyzer (Yokogawa AQ6370B) to be $0.01 \mathrm{~nm}$.

The test Bragg wavelength shifts of the FBG-based pH sensor with the gel layer of $580 \mu \mathrm{m}$ versus different $\mathrm{pH}$ values in the range from 3.0 to 12.0 in the measurement time period of $4 \mathrm{~min}$, are shown in Figs. 5 and 6, in which Fig. 5 gives the different reflection spectra of the FBG-based sensor corresponding to different $\mathrm{pH}$ values, showing that the Bragg wavelength experiences a red shift as the $\mathrm{pH}$ value increases. From Fig. 6, it can be seen that the Bragg wavelength shift is proportional to the changes in the $\mathrm{pH}$ value in the range of $6-12$. The sensitivity in the $\mathrm{pH}$ range of 6-12 was worked out with the result of $52 \mathrm{pm} / \mathrm{pH}$ by using the linear fitting. Additionally, the Bragg wavelength observed in the experiment was a stable value in the time period from $3 \mathrm{~min}$ to $5 \mathrm{~min}$, which was in good 
agreement with the result of B. D. Johnson's study [9]. The study result showed that an FBG-based $\mathrm{pH}$ sensor with practical sensing performance could be got, by optimizing with the gel coated layer of 580 $\mu \mathrm{m}$ and optimum measurement time of $4 \mathrm{~min}$, of which the measurement range was $6 \mathrm{pH}-12 \mathrm{pH}$ value, and the sensitivity was $52 \mathrm{pm} / \mathrm{pH}$.

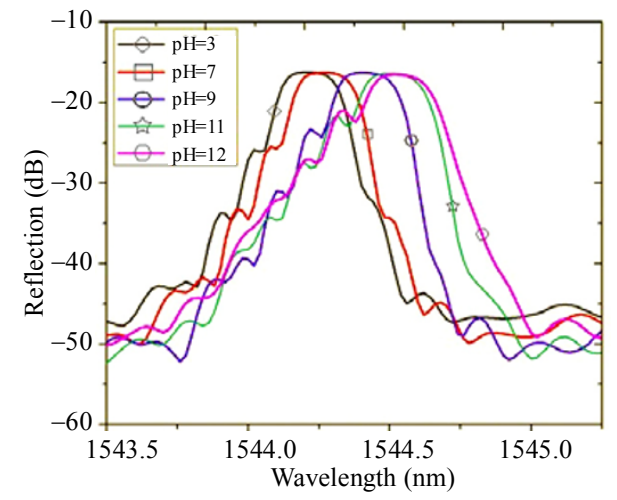

Fig. 5 Reflected spectra of the FBG-based $\mathrm{pH}$ sensor measuring in different $\mathrm{pH}$ values.

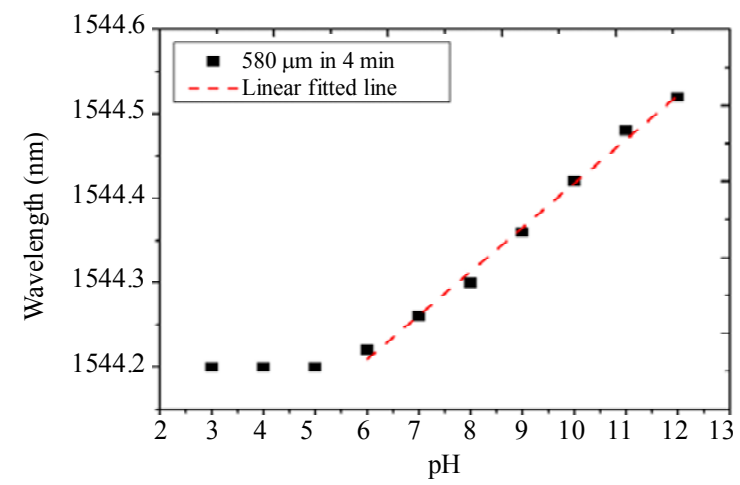

Fig. 6 Spectral shifts of the FBG-based $\mathrm{pH}$ sensor with the coated thickness of $580 \mu \mathrm{m}$ in $4 \mathrm{~min}$.

\section{Conclusions}

With regard to increasing the sensitivity of present $\mathrm{pH}$ FBG sensors, the related factors in determining the sensitivity of the $\mathrm{pH}$ sensors are analyzed in detail. The stress, resulted from the expansion or contraction of the $\mathrm{pH}$ sensitive gel coated on FBGs, versus the thickness of a coated layer is given in curve, which indicates that a higher sensitivity of the FBG-based pH sensor is achieved via increasing the radius of the gel layer coated on FBGs, with a cylindrically symmetrical structure . A multi-thin-layer structure of the gel coated cover was proposed in order to ensure the cylindrical symmetry along the fiber axis when the coated layer was getting thicker, which was implemented via our special "coating over curing" process. With this design and the process, three kinds of FBG-based $\mathrm{pH}$ sensors were built up, with different coating thicknesses of $420 \mu \mathrm{m}, 500 \mu \mathrm{m}$, and $580 \mu \mathrm{m}$, respectively. The corresponding spectral shifts of $0.08 \mathrm{~nm}, 0.13 \mathrm{~nm}$, and $0.22 \mathrm{~nm}$ were detected when the $\mathrm{pH}$ sensors were soaked in the $\mathrm{pH}$ value of 3-9. Besides, the related spectral shifts were also measured in the optimum responding time period of $4 \mathrm{~min}$ for the thickness of $580 \mu \mathrm{m} \mathrm{pH}$-sensitive gel layer with the $\mathrm{pH}$ value changing from $3-12$. The test results with the good performance were realized by optimizing the sensor with the optimum measurement time. Yet, it needs to be mentioned that in the acid $\mathrm{pH}$ value lower than 6 , the design in this paper did not work, which will be the next job to be focused on. Anyway, the analysis, the design, and the experiments done in this paper will provide a good reference for the practical $\mathrm{pH}$ sensor design.

\section{Acknowledgement}

This work is supported in part by UniversityIndustry-Science Partnership Project of Guangdong Province and National Education Ministry (No. 2012B091000155), National Instrument Key Project (No. 2012YQ110205), National 973 Plan Project (No. 2010CB327806). The helps from Dr. Y. Ran (Institute of Photonics Technology, Jinan University) are also gratefully acknowledged.

Open Access This article is distributed under the terms of the Creative Commons Attribution License which permits any use, distribution, and reproduction in any medium, provided the original author(s) and source are credited.

\section{References}

[1] Y. J. Rao, "In-fibre Bragg grating sensors," Measurement Science and Technology, 1997, 8(4): 355-375.

[2] I. Yulianti, A. S. M. Supa'at, S. M. Idrus, N. M. 
Kassim, and A. M. Al-hetar, "Fiber Bragg grating based pH sensor," Proceeding of 2010 International Conf. on Enabling Science and Nanotechnology (ESciNano2010), Kuala Lumpur, Malaysia, 2010: 424-428.

[3] I. Yulianti, A. S. M. Supa'at, S. M. Idrus, and O. Kurdi, "Analysis of $\mathrm{pH}$ sensitive hydrogel coating effect to fiber Bragg grating properties for $\mathrm{pH}$ sensor application," Proceeding of 1st International Congress on Advances in Applied Physics and Materials Science(APMAS, 2011), Antalya, Turkey, 2011: 236-239.

[4] B. N. Shivananju, M. K. Priydarshi, D. R. Mahapatra, G. M. Hegde, and S. Asokan, "pH sensing by single and multi-layer hydrogel coated fiber Bragg grating," Proceeding of 1st International Symposium on Physics and Technology of Sensors (ISPTS-1,2012), Pune, India, 2012: 74-78.

[5] B. Sutapun, M. Tabib-Azar, and A. Kazemi, "Pd-coated elastooptic fiber optic Bragg grating sensors for multiplexed hydrogen sensing," Sensors and Actuators B: Chemical, 1999, 60(1): 27-34.
[6] G. W. C. Kaye and T. H. Laby, Tables of physical and chemical constants, Sixteenth edition. England: Longman, 1995: 45.

[7] G. W. Nieman, J. R. Weertman, and R. W. Siegel. "Tensile strength and creep properties of nanocrystalline palladium," Scripta Metallurgica et Materialia, 1990, 24(1): 145-150.

[8] S. K. De, N. R. Alure, B. Johnson, W. C. Crone, D. J. Beebe, and J. Moore, "Equilibrum swelling and kinetics of pH-responsive hydrogels: models, experiments, and simulations," Journal of Microelectromechanical Systems, 2002, 11(5): 544-555.

[9] B. D. Johnson, D. J. Beebe, and W. C. Crone. "Effects of swelling on the mechanical properties of a pH-sensitive hydrogel for use in microfluidic devices," Materials Science and Engineering C, 2004, 24(4): 575-581.

[10] Y. Ran, L. Jin, Y. N. Tan, L. P. Sun, J. Li, and B. O. Guan, "High-efficiency ultraviolet inscription of Bragg grating in microfibers", IEEE Photonics Journal, 2012, 4(1): 181-186. 